\title{
Erken Postpartum Dönem Meme Sorunlarında Kanıt Temelli Tamamlayıcı ve Destekleyici Bakım Uygulamaları
}

\section{Evidence Based Traditional and Complementary Medicine Applications in Early Postpartum Period Breast Problems}

\author{
Ayşenur Durmuş $^{1}$ (iD) Özlem Can Gürkan ${ }^{2}$ (DD \\ ${ }^{1}$ Ardahan Üniversitesi Sağlık Hizmetleri Meslek Yüksekokulu Çocuk Bakımı ve Gençlik Hizmetleri Bölümü, Ardahan, TÜRKIYE \\ ${ }^{2}$ Marmara Üniversitesi Sağlık Bilimleri Fakültesi Hemşirelik Bölümü Doğum ve Kadın Hastalıkları Hemşireliği Anabilim Dalı, \\ İstanbul, TÜRKIYE \\ Geliș tarihi/ Date of receipt: 08/07/2020 Kabul tarihi/ Date of acceptance: 22/09/2020 \\ (C) Ordu University Faculty of Health Sciences, Department of Nursing, TURKEY, Published online 30/09/2020
}

öz

Doğum sonrası dönem anne ve bebek için fiziksel ve ruhsal yönden pek çok değişikliğin olduğu bir süreçtir. Erken postpartum dönemde emzirmenin bir an önce başlatılması ve etkili bir şekilde devamının sağlanması anne, bebek sağlığı açısından çok önemlidir. Bebeğin anne sütü ile beslenmesinin kesintiye uğramasının nedenlerinden birisi olan meme başı ağrısı ve çatlağının erken postpartum dönemde tedavisinin yapılması ve emzirmenin kesintiye uğramasının önüne geçilmesi son derece önemlidir. Bu çalışma emziren annelerde erken postpartum dönemde meydana gelen meme sorunlarının tedavisinde kullanılan tamamlayıcı ve destekleyici bakım uygulamalarının kanıt düzeylerini incelemek amacıyla hazırlanmıştır. Çalışmamızda Scopus, Pubmed, Science of Direct, Google Scholar veri tabanlarında "Meme Başı Sorunları", "Meme Başı Ağrısı", "Nipple Problems", "Nipple Pain", anahtar kelimeleri ile tarama yapılmış ve çalışma konusu ile uyumlu 50 yayına ulaşılmış olup, tam metnine ulaşılan Türkçe veya İngilizce araştırma makaleleri, sistematik derlemeler, meta analiz çalışmaları incelenerek son 10 yıl içerisinde yayınlanan toplam 28 makale çalışmamıza dahil edilmiştir. Erken postpartum dönemde görülen meme sorunlarını gidermedeki etkililiği kanıt düzeyi yüksek olan çalışmalarla bildirilmiş ve en çok uygulanan müdahaleler derlememize dahil edilmiştir. Sonuç olarak emzirme sürecinde kadınlara zeytin yağı, lanolin, aloe vera ve nane suyu kullanımı önerilebilir. Konuyla ilgili daha fazla randomize kontrollü çalışmanın yapılması önemlidir.

Anahtar kelimeler: Emzirme sorunları, meme sorunları, tamamlayıcı ve destekleyici bakım

\begin{abstract}
The postpartum period is a process which occur many physical and mental changes for the mother and baby.It is very important for mother and baby health to start breastfeeding as soon as possible in the early postpartum period, and ensuring an effective continuation is very important for mother and baby health. It is important to treat nipple pain and crack in the early postpartum period and prevent breastfeeding interruption, which is one of the reasons for interruption of breastfeeding of the baby. This study was prepared to examine the evidence levels of complementary and supportive care practices used in the treatment of breast problems in breastfeeding mothers in the early postpartum period.

In our study, Scopus, Pubmed, Science of Direct, Google Scholar databases were scanned with the keywords "Nipple Problems", "Nipple Problems", "Nipple Problems", "Nipple Pain" and 50 publications compatible with the subject of the study were reached. A total of 28 articles published in the last 10 years were included in our study by examining Turkish or English research articles, systematic reviews, meta-analysis studies whose full text was reached.. Its effectiveness in eliminating breast problems seen in the early postpartum period has been reported in studies with a high level of evidence, and the most applied interventions have been included in our review.

As a result, olive oil, lanoline, aloe vera and mint juice can be recommended to women during breastfeeding. It is important to conduct more randomized controlled studies on the subject.

Keywords: Breastfeeding problems, breast problems, traditional and complementary medicine

ORCID IDs of the authors: AD: 0000-0003-0361-8036; ÖCG: 0000-0002-5608-6208

Sorumlu yazar/Corresponding author: Öğr. Gör. Ayşenur Durmuş

Ardahan Üniversitesi Sağlık Hizmetleri Meslek Yüksekokulu Çocuk bakımı ve Gençlik Hizmetleri Bölümü, Ardahan, TÜRKIYYE

e-posta/e-mail: aysenurdurmus@ardahan.edu.tr

Atıf/Citation: Durmuş A, Can Gürkan Ö. (2020). Erken postpartum dönem meme sorunlarında kanıt temelli tamamlayıcı ve destekleyici bakım uygulamaları. Ordu Üniversitesi Hemşirelik Çalışmaları Dergisi, 3(2), 185-192.

DOI: $10.38108 /$ ouhcd.761903
\end{abstract}




\section{Giriş}

Bebeğin büyüme ve gelişmesi için eşsiz bir besin maddesi olan anne sütü, kadının en önemli yaşam dönemlerinden biri olan laktasyon döneminde üretilir. Anne sütü, yenidoğan morbidite ve mortalite oranlarını azaltan, intrauterin yaşam sonrası büyüme ve gelişme için yeterli besin içeriklerini barındıran, fiziksel, ruhsal ve zihinsel yönden yenidoğanın gelişimi için gerekli tüm sıvı, enerji ve besin öğelerini içeren, biyoyararlanımı yüksek, sindirimi kolay, ekonomik ve sosyal açıdan pek çok yararı bulunan doğal bir besindir (Çakmak ve Dengi, 2019). Dünya Sağlık Örgütü (DSÖ) ve Birleşmiş Milletler Çocuklara Yardım Fonu (United Nations International Children's Emergency Fund (UNICEF) gibi birçok kuruluş ilk 6 ay boyunca bebeğin sadece anne sütü ile beslenmesini, devamında ise güvenli ek gida ile birlikte 2 yaş ve üzerine kadar anne sütü ile beslenmesinin devam ettirilmesini önermektedir (WHO ve UNICEF, 1995). Ülkemizde, TNSA 2018 verilerine göre 6 aydan küçük bebeklerin sadece \%41'inin anne sütüyle beslendiği ve 6 . aydan sonra bu oranın hızla azaldığı bildirilmiştir (TNSA, 2018).

Yalnızca anne sütü alan bebeklerin oranı 01 ay arasinda $\% 59,2-3$ ay arasinda $\% 45$ ve $4-5$ ay bebekler arasında \%14'dür. Altı aydan küçük bebeklerin sadece anne sütü ile beslenmesi gerektiği önerisinin aksine, bebeklerin \%23'ü anne sütü olmayan diğer sütlerle ve bebeklerin $\% 12$ 'si anne sütüyle birlikte ek gida almaktadır (TNSA, 2018).

Ülkemizde doğum sonrası emzirme oranlarının istenilen düzeyde olmaması, doğum sonrası dönemde annenin emzirmeye teşvik edilmesi ve emzirmeyi engelleyen problemlerin değerlendirilerek ortadan kaldırılması gerekliliğini doğurmaktadır. Doğum sonrası dönemde kadınların emzirmeyi başlatma ve sürdürme kararına katkıda bulunan birçok faktör olmasına rağmen, çoğu kadının kendi seçiminden ziyade algılanan zorluklar nedeniyle emzirmeyi erken dönemde birakmaktadır (Campos ve ark., 2018; Juliana ve ark., 2016; Neto ve ark., 2018). Doğum sonrası erken dönemde emziren kadınlar yaygın olarak meme başı ağrısı ve çatlağı gibi zorluklar yaşamakta, yaşanan bu zorluklar sebebiyle de doğumdan sonraki ilk 6 hafta içerisinde bebeğin beslenme şeklini değiştirebilmektedir (Abou-Dakn ve ark., 2011; Jackson ve ark., 2016; Niazi ve ark., 2018; Shanazi ve ark., 2015; Sailo ve ark. 2018)

Bebeğin beslenme şeklinin değiştirilmesinde annenin kendi sütünü yetersiz görmesini takiben ikinci ana sebepler arasında meme başı çatlakları yer almaktadır (Niazi ve ark., 2018; Page ve ark., 2003). Meme ucu ağrısı ve çatlağı emziren kadınların $\% 80$ ila \%90'ında görülür (Shanazi ve ark., 2015). Meme baş1 ağris1 postpartum dönemin ilk bir haftası içinde \%45-90 oranında görülürken, meme başı çatlağı postpartum ilk 3 günde \%15-41 oranında görülmektedir (Kirlek ve ark., 2013; Niazi., 2018). Emzirmenin kesilmesi bebeği anne sütündeki temel besinlerden, büyüme faktörlerinden ve önemli immünolojik bileşenlerden mahrum ettiği gibi doğum sonrası anne ve bebek bağlanmasının gelişmesine de engel olabilir (Campos ve ark., 2018). Doğum sonrası dönemde görülen meme sorunlarının erkenden tespit edilmesi ve iyileşmesinin sağlanarak annenin emzirmeyi bırakmamasının ve devam ettirmesinin sağlanması son derece önemlidir.

Emzirmenin başlatılması, özendirilmesi ve devamının sağlanması sürecinde hemşirelere/ebelere emzirmeyi destekleme konusunda önemli görevler düşmektedir. Postpartum süreçte kadınlara emzirme eğitimi vermek, emzirmeyi desteklemek ve oluşan meme sorunlarının önlenmesine yardımcı olmak doğum sonu dönemde hemşirelerin/ ebelerin önemli görevlerindendir (Dyson ve ark., 2005).

Meme sorunlarının erken dönemde fark edilip tedavi edilmesi son derece önemlidir. Tedavi edilmeyen meme çatlakları şiddetli ağrı, meme ucu kanaması, yetersiz süt salgısı, mastitis ve meme apsesi gibi sorunlara yol açabilir (Jackson ve ark., 2017; Kent ve ark., 2015). Bu sorunlar beraberinde anne sütünün üretimini ve salgılanmasını azaltır, son olarak 
annede stres yaratır ve oksitosin üretimi üzerindeki engelleyici etkileri nedeniyle emzirmeyi durdurur. Bu sebeplerle emziren anneler meme ucu sorunları nedeniyle kliniğe başvurarak yardım ararlar (Şahin ve ark., 2013).

Postpartum dönemde meme sorunlarının önlenmesi ve tedavisinde son y1llarda çay kompresleri, lokal sicak ve soğuk uygulama, nane suyu, lanolin ve hidrojel pansuman, zeytinyağı, çiğ soğan, kına, ruj, tereyağı, süt kaymağı ve mevzer yağı en sik kullanılan uygulamalardır (Çelik ve ark., 2012; Dennis ve Jackson, 2014; Erenoğlu ve ark., 2017; Kirlek ve Balkaya, 2013; Vieira ve ark., 2013)

Kadınlar, postpartum dönemde meme sorunlarının önlenmesi ve tedavisinde tamamlayıc1 ve destekleyici bakım uygulamalarını kullanmalarına rağmen bunların kanıt düzeylerini inceleyen sınırlı sayıda çalışma mevcuttur. Bu gerekçe ile yola çıkarak, bu çalışma erken postpartum dönemde meme başı sorunlarının önlenmesinde ve tedavisinde kullanılan kanıt temelli tamamlayıcı ve destekleyici bakım uygulama yöntemlerini incelemek amaciyla hazırlanmıştır. Elde edilen makalelerin kanıt düzeyi Joanna Briggs Enstitüsü'nün kabul ettiği kanıt düzeyi sinıflandırmasına göre değerlendirilmiştir (Tablo 1) (Joanna Briggs, 2003).

\section{Erken Postpartum Dönem Meme Sorunlarında Kullanılan Tamamlayıcı ve Destekleyici Bakım Uygulamaları}

DSÖ ve UNICEF emziren annelerin memelerini her emzirme öncesi ve sonrasında yıkamaya gerek olmadığını, sabun kullanmamasını veya bir havluyla sertçe ovmamasını, yıkamanın doğal yağları deriden uzaklaştırdığını ve sorunları daha olası hale getirdiğini bildirmektedir. Doğum sonrası meme bakımında, emzirme öncesi ve sonrası eller çok iyi yıkanmalı, her emzirme sonrası annenin kendi parmağıyla sağdığı az miktar anne sütünü meme başı ve areola üzerine biraz sürmesi ve kurumaya bırakması gerekmektedir (WHO/UNICEF, 1993).
Tablo 1. Hemşirelikte kanıt düzeyi sınıflamaları Joanna Briggs Enstitüsü kanıt düzeyi sınıflaması (Joanna Briggs, 2003)

\begin{tabular}{|l|l|}
\hline Düzey & \multicolumn{1}{|c|}{ Kanıt tipi } \\
\hline I & $\begin{array}{l}\text { RKÇ'larla yapılmış sistematik } \\
\text { incelemelerden elde edilen kanıtlar. }\end{array}$ \\
\hline II & $\begin{array}{l}\text { En az bir, iyi tasarlanmış, RKÇ'dan } \\
\text { elde edilen kanıt. }\end{array}$ \\
\hline III.1 & $\begin{array}{l}\text { Randomize olmayan iyi tasarlanmış } \\
\text { kontrollü çalışmalardan elde edilen } \\
\text { kanıt. }\end{array}$ \\
\hline III.2 & $\begin{array}{l}\text { Birden fazla merkez/grup tarafindan } \\
\text { yapılmış, iyi tasarlanmış kohort ya da } \\
\text { vaka-kontrol çalışmalarından elde } \\
\text { edilen kanıt. }\end{array}$ \\
\hline III.3 & $\begin{array}{l}\text { Girişimli ya da girişimsiz çoklu zaman } \\
\text { serilerinden elde edilen kanıt. } \\
\text { Kontrolsüz deneysel çalışmaların } \\
\text { etkileyici sonuçları. }\end{array}$ \\
\hline IV & $\begin{array}{l}\text { Klinik deneyimlere dayalı, saygın } \\
\text { otoritelerin görüşleri, tanımlayıcı } \\
\text { çalışmalar ya da uzman komite } \\
\text { raporları. }\end{array}$ \\
\hline
\end{tabular}

Meme ucu ağrısının ve çatlaklarının giderilmesinde anne sütü ile yapilan meme bakımının, önleyici etkiye sahip olduğu birçok çalışma ile kanıtlanmış ve kontrendike olmadığ1 gösterilmiştir (Eshgizade ve ark., 2016; Gharakhani ve ark., 2018; Güngör ve ark., 2013, Walker M., 2013). Meme ucu sorunlarının giderilmesinde kullanılan pek çok tamamlayıcı ve destekleyici bakım uygulaması olmakla birlikte, bu uygulamaların etkileri ve kanıt düzeyleri çalışmalarla gösterilmiştir (Tablo 2). 
Tablo 2. Erken postpartum dönemde görülen meme sorunlarında kullanılan uygulamaların kanıt düzeyleri

\begin{tabular}{|l|l|r|}
\hline Ürün & Etki & $\begin{array}{l}\text { Kanıt } \\
\text { Düzeyi }\end{array}$ \\
\hline Zeytinyağı & $\begin{array}{l}\text { Meme ucu ağrısını } \\
\text { azaltma ve meme ucu } \\
\text { çatlağını önleme }\end{array}$ & I, II \\
\hline $\begin{array}{l}\text { Lanolinli } \\
\text { göğüs } \\
\text { kalkanları }\end{array}$ & $\begin{array}{l}\text { Meme ucu ağrı algısını } \\
\text { azaltma }\end{array}$ & I \\
\hline Lanolin & $\begin{array}{l}\text { Travmatik meme başı } \\
\text { ağrısını giderme }\end{array}$ & II \\
\hline Nane suyu & $\begin{array}{l}\text { Meme başı travması, } \\
\text { meme ağrısı ve yara } \\
\text { oluşumunu engelleme }\end{array}$ & $\begin{array}{l}\text { Meme ucu çatlaklarını } \\
\text { iyileştirme, } \\
\text { irritasyonları giderme }\end{array}$ \\
\hline Aloe vera & II \\
\hline $\begin{array}{l}\text { Çay } \\
\text { kompresi }\end{array}$ & $\begin{array}{l}\text { Travmatik meme } \\
\text { üzerindeki } \\
\text { semptomları giderme }\end{array}$ & \multicolumn{2}{|l}{} \\
\hline
\end{tabular}

\section{Zeytinyă̆ı Uygulaması}

Zeytinyağı kolay erişilebilir, doğal ve ucuz bir yağdır (Güngör ve ark., 2013). Flavonoidler, antioksidan, antibakteriyel ve antifungal bileşiklerden oluşur. Zeytinyağı 3 ana antioksidan içerir. Bunlar; E vitamini, polifenoller ve fitosterollerdir (Nageeb ve ark., 2018). Antioksidan ve antienflamatuar özelliklere sahip oleuropein, serbest radikal ve hücre onarım özelliklerine sahip Oleocanthal içeren zeytinyağı analjezik ve antienflamatuardır. Aynı zamanda güçlü antioksidan ve antimikrobiyal özelliklere sahiptir ve uzun zamandır yara iyileşmesi için kullanılmaktadır. Ayrıca zeytinyağının anne sütüne yakın linoleik asit içerdiği bilinmektedir (Pezeshki ve ark., 2020).

Bazı çalışmalar zeytinyağı uygulamasının meme başı çatlağı görülme olasılığını azalttığını ve uygulamaların emzirmeyi olumsuz etkilemediğini belirtmektedir (Kanıt düzeyi III.1 - Güngör ve ark.,2013; Kirlek, 2013)

Zeytinyağı ile yapılan meme bakımının meme ucu ağrısı ve meme ucu çatlağını önlemede olumlu etkisi olduğu, meme başı çatlağı oluşumunu engellediği, erişilebilir ve güvenli olduğu çalışmalarda bildirilmiştir (Kanıt düzeyi I- Karaçam ve Sağlık .2018; Pzeshki ve ark., 2020), (Kanıt düzeyi IICondero ve ark. 2015; Esghizade ve ark., 2016; Güngör ve ark., 2013; Kirlek ve Oğuz, 2013; Nagaeeb ve ark., 2018; Oğuz ve ark., 2014). Kolay elde edilebilir, ucuz ve yan etkisi olmayan bir yöntem olması nedeniyle meme ucu çatlaklarının oluşumunun önlenmesi ve meme ucu ağrısının tedavisinde alternatif bir seçenek olarak kullanılabilir (Oğuz ve ark., 2014).

\section{Lanolin Uygulama}

Lanolin, nemli bir cilt oluşturarak yaraları önler. Bunun yanısıra epitelizasyonu artırarak yaraları iyileştirir. Ester, lanolinin aktif bileşenidir. Esterler, nemli bir ortamda yara iyileştirme özelliğinin yanı sıra antienflamatuar, anti-bakteriyel, cilt koruyucu ve iyileştirici bariyere sahiptir. Yaralanan dokunun nemini koruyarak iyileşmeyi arttırmasının yanında bu kimyasallara maruz kalma miktarını ve süresini azaltarak ağrıyı hafifletmektedir (Asaadi ve ark., 2016; Niazi ve ark., 2018; Pezeshki ve ark., 2020).

Niazi (2018) lanolin ve semizotu kreminin emziren annelerin meme sorunları üzerine etkisine bakmış ve semizotu kreminde iyileşmenin lanolin grubundan daha hızlı olduğunu bulmuştur (Kanıt Düzeyi II - Niazi ve ark., 2018). Literatürde lanolin ile yapılan meme bakımının meme ucu çatlağını ve ağrısını önleyici etkiye sahip olduğunu gösteren çalışmalar mevcuttur (Niazi ve ark., 2018; Saeidi ve ark., 2015; Shanazi ve ark., 2015; Walker, 2013). Jackson ve Dennis (2017) çalışmalarında lanolinin meme ucu ağrısını azaltmadığını, emzirmenin süresini, sıklığını, sayısını etkilemediğini sadece annenin memnuniyetini arttırdığını bildirmiştir (Kanıt düzeyi II) (Jackson ve Denniz, 2017). 
Shanazi (2015) yaptığı çalışmasında lanolinin travmatik meme başı ağrısını gidermede önerilebilir bir yöntem olduğunu bildirmiştir (Kanıt düzeyi II) (Shanazi ve ark., 2015). Uluslar arası kurul sertifikalı emzirme danışmanları (International Board Certified Lactation Consultants) ve Dünya çapinda emzirme desteği sağlayan bir kuruluş olan La Leche League International tarafindan kullanılması önerilen müdahale lanolin uygulamasıdır (Kanıt Düzeyi IV)

Sağlık hizmeti sağlayıcıları genellikle ağnılı ve/veya hasarlı meme başı sorunlarını tedavi etmek için lanolin uygulamasını önermektedirler. Ancak lanolinin etkisini spesifik olarak değerlendiren randomize kontrollü bir çalışma yoktur (Jackson ve Dennis, 2018).

Dennis ve ark., 2014, yaptıkları meta analizinde meme başı ağrısı yaşayan ve emziren 656 kadın arasında kullanılan müdahaleleri bildirmişlerdir. Gliserin jel sargıları, lanolinli gögüs kalkanları, tek başına lanolin veya çok amaçlı lanolinli meme merhemi hakkında yeterli kanıt bulunmadığını, meme başı ağrı algısında önemli ölçüde etkili olduğunu bulmuşlardır (Kanıt Düzeyi I Dennis ve ark., 2014).

\section{Nane Uygulama}

İran'a özgü bir bitki olan nane otu, cilt uyuşması, yanıklar, yara izleri, kaşıntı ve iltihapların tedavisinde yaygın olarak kullanılmaktadır (Shanazi ve ark., 2015).

Nane antiseptik, sakinleştirici ve yatıştırma etkilerine sahiptir ve cilt tahrişlerini hafifletmek ve çatlaklara karşı direnç geliştirmek için kullanılır (Asadi ve ark., 2018). Mentol ve fenol bileşiklerinin varlığı nedeniyle, bakteri ve mantarların aktivitesini de inhibe edebilir. Nane esansiyel yağının özellikle merhem topikal kullanımının, enflamatuar aşamaların ve doku enfeksiyonunun önlenmesi yoluyla iyileşme süreci üzerinde olumlu bir etkisi vardır. Topikal olarak kullanıldığında bu bitkisel preparat, anne ve bebek için hiçbir yan etkiye sahip değildir (Bahar ve ark., 2018; Linari ve Castaman, 2015). Bahar ve ark. (2018) yaptıkları çalışmada meme ucuna anne sütü sürmenin nane kremi ve nane çayından daha etkili olduğunu bulmuşlardır (Kanıt düzeyi II) (Bahar ve ark., 2018). Thabet ve ark. (2013) nane suyu, anne sütü ve kuru, temiz tutma yöntemlerini karşılaştırdıkları randomize kontrollü çalışmada nane suyu grubunda meme ucu çatlağının daha az görüldüğünü bildirmişlerdir (Kanıt düzeyi II- Thabet ve ark., 2013). Kanıt düzeyi II olan başka bir çalışmada nanenin travmatik meme uçlarının tedavisine katkısı lanolin ve dekspanteno'nunkine benzer olarak bulunmuş, travmatik meme uçlarının iyileşmesinde annelere önerilebileceği belirtilmiştir (Shanazi ve ark., 2015). Kanıt düzeyi II çalışmalar nane suyu uygulayan emziren annelerin daha az yara, daha az meme başı travması ve daha az meme ağrısı yaşadığını, anne sütünden daha etkili olduğunu bildirmişlerdir (Abdel ve ark.,2019; Naser, 2017; Sailo ve ark., 2018; Thabet ve ark., 2013). Nane suyu, nane jeli, nane çayı gibi doğal yöntemlerin etkili tedavi olduğu ve kesin etkinliğini belirlemek için daha fazla çalışmaya ihtiyaç olduğu açıklanmıştır (Asadi ve ark., 2018).

\section{Aloe vera Uygulama}

Aloe vera sahip olduğu iyileştirici, antienflamatuar, antiviral, antibakteriyel, antifungal, antimikrobiyal, nemlendirici özellikler sayesinde ciltteki yaranın onarılmasını sağlar (Pezeshki ve ark., 2020; Tafazoli ve ark., 2010). Meme sorunlarına karşı aloe veranın analjezik ve antiinflamatuar etkileri kanıtlanmıştır (Niazi ve ark., 2018). Anne sütü ile aloe vera jelinin karşılaştırıldığ kanıt düzeyi II olan bir çalışmada postpartum dönemdeki emziren kadınlara 10 gün boyunca aloe vera jeli uygulanmış ve aloe vera jeli uygulamasinin kadinlarda meme irritasyonunun tedavisinde iyileştirici etkisi olduğunu, herhangi bir yan etkisi olmadığını bildirmişlerdir (Alamolhoda ve ark., 2014). Tafazoli 2010 yılında lanolin ile aloe veranın meme yaraları üzerine etkisini karşılaştırdığ 1 çalışmasında aloe veranın lanoline göre meme başı çatlaklarını gidermede daha etkili olduğu 
sonucuna varmıştır (Kanıt düzeyi II - Tafazoli ve ark., 2010).

Kanıt düzeyi II olan bir başka çalışmada emziren annelerin meme ucuna anne sütü, zeytinyağı ve aloe vera uygulamış ve sonunda, üç grup arasında ağrı ve meme ucu yarası açısından anlamlı bir fark olduğunu aloe vera grubunda diğer gruplara göre daha az meme ucu çatlağı olduğunu, daha etkili bir yöntem olduğunu bildirmiştir (Eshgizade ve ark., 2016). Kanıt düzeyi II çalışmalarda aloe veranın meme başı yara ve ağrısı üzerine etkisine bakılmış ve aloe veranın yara iyileşmesi üzerinde etkili olduğu bulunmuştur (Saeidi ve ark., 2015; Eshgizade ve ark., 2016) Kanıt düzeyi I olan çalışmalar aloe veranın maliyeti düşük ve yan etkilerinin sınırlı olması göz önüne alındığında, meme ucu çatlaklarını iyileştirmek için kullanımını önermektedir (Pezeshki ve ark., 2020).

\section{Çay Kompresi Uygulama}

Doğum sonu dönemde meme sorunlarının giderilmesinde kullanılan etkili yöntemlerden birisi de sicak veya soğuk çay kompresi uygulamasıdır. Lokal çay kompresi uygulamasının tedavi edici etkisi, çayın bileşiminde yer alan tannik asitten gelmektedir. Tannik asit, mukoz membran tarafından absorbe edilmekte ve aşınmış ciltte nekroz gelişimini önlemektedir. Ayrıca kısmen antiseptik özelliğe de sahiptir. Lavergne (1995) araştırmasında meme bakımında sıcak su ve çay kompresi uygulamasını karşılaştırmış ve çay kompresinin tedavi verilmeyen gruba göre etkili bir yöntem olduğunu belirlemiştir (Lavergne, 1997). Kanıt düzeyi II olan bir çalışmada 150 emziren anne örnekleme alınmış ve anne sütü, çay kompresi lanolin uygulama grubu olarak 3'e ayrılmıştır. Çay kompresi uygulayan annelerden günde $4 \mathrm{kez} 5$ 10 dakika boyunca çay paketini meme üzerine koymaları istenmiştir. Çalışma sonucunda çay kompresi, lanolin ve anne sütünün aynı etkiye sahip olduğu bildirilmiştir (Ahmed ve ark., 2015)

\section{Sonuç}

Emzirme anne ve bebek sağlıği üzerinde önemli etkileri olan bir dönemdir. Bu dönemde annenin etkili bir şekilde emzirmesi ve bebeğin anne sütünden en iyi şekilde faydalanabilmesi için meme üzerinde gelişebilecek sorunların minimalize edilmesi gerekmektedir. Postpartum dönemde görülen meme sorunlarının giderilmesi için çeşitli tamamlayıcı ve destekleyici yöntemler kullanılmaktadır. Yapılan birçok çalışma ile tamamlayıcı ve destekleyici yöntemlerin meme sorunlarını gidermedeki etkililik düzeyleri ortaya koyulmuştur.

Tamamlayıcı ve destekleyici bakım uygulamaları anneler tarafindan meme sorunlarını gidermek için etkin bir şekilde kullanılabilir. Meme sorunlarının giderilmesinde nane, aloe vera, lanolin, zeytinyağı gibi tamamlayıcı ve destekleyici uygulamaların anne sütünün meme ucuna sürülmesinden daha etkili olduğu, meme başı ağrısı ve çatlaklarının gelişmesini önlediği, iyileşmeyi hızlandırarak annenin memnuniyetini arttırdığı görülmüştür. Geniş çaplı ve kanıta dayalı araştırmaların eksikliğine rağmen, yapılan birçok araştırma sonuçlarında, nemli meme bakımının, meme ucunda oluşabilecek tahribatı yüksek oranda önlediği ve deri bütünlüğü bozulmuş meme uçlarına yönelik tedavide, temiz kuru tutma yönteminden daha etkili olduğu bildirilmektedir Meme başı travması ile baş edebilmek ve etkili bir bakım sağlayabilmek için daha fazla örneklem grupları ile yapılacak olan kanıt düzeyi yüksek çalışmalara ihtiyaç vardir.

\section{Araştırmanın Etik Yönü/ Ethics Committee Approval: \\ Hakem/Peer-review: Dış hakem değerlendirmesi. \\ Yazar Katkısı/Author Contributions: Fikir/kavram: $\mathrm{AD}$, ÖCG; Tasarım: AD, ÖCG; Veri toplama: AD, ÖCG; Veri işleme: AD, ÖCG, Analiz ve/veya Yorum: $\mathrm{AD}$, ÖCG; Kaynak tarama: AD, ÖCG; Makalenin Yazımı: AD, ÖCG; Eleştirel inceleme: AD, ÖCG \\ Çıkar çatışması/Conflict of interest: Yazarlar arasında çıkar çatışması bulunmamaktadır. \\ Finansal Destek/Financial Disclosure: Çalışma için herhangi bir finansal destek alınmamıştır.}




\section{Çalışma Literatüre Ne Kattı?}

- Çalışma, günümüzde, erken postpartum dönemde görülen meme sorunlarının azaltılmasında kullanılan, tamamlayıcı ve destekleyici bakım uygulamalarının kanıt düzeyleri hakkında bilgi sağlayarak literatüre katkıda bulunacaktır.

- Çalışma, ebe ve hemşirelere, erken postpartum dönemde meme sorunlarının azaltılmasında ve giderilmesinde kullanabilecekleri tamamlayıcı ve destekleyici bakım uygulamaların neler olduğuyla ilgili bilgi sağlayacaktır.

\section{Kaynaklar}

Abdel NI, Hafez S, Ghaly A. (2019). Effect of Breast Milk, Peppermint Water and Breast Shell on Treatment of Traumatic Nipple in Puerperal Lactating Mothers. International Journal of Novel Research in Healthcare and Nursing, 6(3), 692-709.

Abou-Dakn M, Fluhr JW, Gensch M, Wöckel A. (2011). Positive effect of HPA lanolin versus expressed breastmilk on painful and damaged nipples during lactation. Skin Pharmacology Physiology, 24 (1), 27 35.

Ahmed E, Mohamed H, Abu-talib Y. (2015). Evidence Based Guideline Using to Alleviate Traumatic Nipple among Nursing Mothers. World Journal of Nursing Sciences, 1 (3), 35-44.

Alamolhoda SH, AmirAliAkbari S, Baghban AA, Esmaili S. (2014). Effects of aloe vera gel on breast fissures in breastfeeding women. Pajoohandeh Journal, 19 (1), 13-17.

Asaadi N, Kariman N, Shahrahmani H, Ghalandari S, Khodakarami N. (2016). A systematic review of clinical trials in the treatment of sore nipple and nipple pain in breastfeeding women. The Iranian Journal of Obstetrics, Gynecology and Infertility, 19 (6), 22-33.

Campos TM, Traverzim MAS, Sobral APT, Bussadori SK, Fernandes KSP, Motta LJ, Makabe S. (2018). Effect of LED therapy for the treatment nipple fissures. Medicine, 97 (41), 1-6.

Condero MJ, Villar NM, Barrilao RG, Cortes ME, Lopez AM. (2015). Application of extra virgin olive oil to prevent nipple cracking in lactating women. World Views Evid Based Nurse, 12 (6), 364-369.

Çakmak S, Dengi ASD. (2019). Postpartum evaluation of the mothers' knowledge about breastfeeding and the importance of breast milk. Türkiye Aile Hekimliği Dergisi, 23 (1), 9-19.

Dennis CL, Jackson K, Watson J. (2014). Interventions for treating painful nipples among breastfeeding women. Cochrane Database of Systematic Reviews, 12. Art. No.: CD007366. DOI: 10.1002/14651858.CD007366.pub2
Dyson L, McCormick FM, Renfrew MJ. (2005). Interventions for promoting the initiation of breastfeeding. Cochrane Database of Systematic Reviews, 2. Art. No.: CD001688. DOI: 10.1002/14651858.CD001688.pub2

Erenoğlu R, Can R, Tambağ H, Akdeniz Ş. (2017). Birth-the postpartum period regarding traditioonal applications of women in rural areas: The Example Karaksi. Uluslararası Kibris Üniversitesi Folklor/Edebiyat, 23 (90), 179-196.

Eshgizade M, Moghaddam MB, Moghaddam HM, Mahmoudian A, Mina M. (2016). Comparison of the effect of olive oil, aloe vera extract and breast milk on healing of breast fissure in lactating mothers: A Randomized Clinical Trial. Qom University Medical Sciences Journal, 10 (3), 19-27.

Gharakhani Bahar T, Oshvandi K, Zahra Masoumi S, Mohammadi Y, Moradkhani S, Firozian FA. (2018). A Comparative study of the effects of mint tea bag, mint cream, and breast milk on the treatment of cracked nipple in the lactation period: A Randomized Clinical Trial Study. Iranian Journal of Neonatology, 9 (4), 72-79.

Güngör AN, Oğuz S, Vurur G, Gencer M, Uysal A, Hacivelioglu S. (2013). Comparison of olive oil and lanolin in the prevention of sore nipples in nursing mothers. Breastfeeding Medicine, 8(3), 334-335.

Jackson KT, Dennis CL. (2017). Lanolin for the treatment of nipple pain in breastfeeding women: a randomized controlled trial. Maternal \& Child Nutrition, 13, 3-14.

Joanna Briggs Institue. (2003). JBI Levels of Evidence. Erişim Tarihi: 02.08.2020, https://joannabriggs.org/.

Karaçam Z, Sağlık M. (2018). Breastfeeding problems and interventions performed on problems: Systematic review based on studies made in Turkey. Türk Pediatri Arşivi, 53 (3), 134-148.

Kent JC, Ashton E, Hardwick CM, Rowan MK, Chia ES, Fairclough KA, Menon LL, Scott C, MatherMcCaw G, Navarro K, Geddes DT. (2015). Nipple pain in breastfeeding mothers: incidence, causes and treatments. International Journal of Environmental Research and Public Health, 12 (10), 12247-12263.

Kirlek F. (2013). The effects of breast milk and olive oil on prevention of nipple pain and nipple cracks at early postpartum period. Hemşirelikte Araştırma Geliştirme Dergisi, 15 (2), 17-34.

Lavergne NA. (1997). Does application of tea bags to sore nipples while breastfeeding provide effective relief?. Journal of Obstetric, Gynecologic, and Neonatal Nursing : JOGNN. 26 (1), 53-58.

Linari S, Castaman G. (2015). Clinical manifestations and management of gaucher disease. Clinical Cases Mineral Bone Metabolism, 12 (2), 157-164. 
Murimi M, Dodge CM, Pope J, Erickson D. (2010). Factors that influence breastfeeding decisions among special supplemental nutrition program for women, infants, and children participants from central louisiana. Journal of the American Dietetic Association, 110, 624-627.

Nageeb H, Fadel EA, Hassan NF. (2018). Olive oil on nipple trauma among lactating mothers. Mansoura Nursing Journal (MNJ), 6 (1), 159-170.

Naser E, Nour S, Gonied A, Shaban R. (2017). Effect of peppermint water versus expressed breast milk on nipple trauma among lactating primiparous. Zagazig Nursing Journal, 13 (1), 227-242.

Neto CM, Giesta RO, Albuquerque RS, Souza SC, Fernandes APS, Mondin B. (2018). Comparative study of the use of hpa lanolin and breast milk for treating pain associated with nipple trauma . Revista Brasileira Ginecologia Obstetricia, 40 (11), 664-672.

Niazi A, Rahimi VB, Soheili-Far S, Askari N, Rahmanian-Devin P, Sanei-Far Z, Sahebkar A, Rakhshandeh H, Askari VR. (2018). A systematic review on prevention and treatment of nipple pain and fissure: Are they curable?. Journal of Pharmacopuncture, 21(3), 139-150.

Niazi A, Yousefzadeh S, Rakhshandeh H, Esmaily H. (2018). Comparison of the effects of purslane cream and lanolin for treatment of breast fissure on lactation self-efficacy: a randomized clinical trial. The Iranian Journal of Obstetrics, Gynecology and Infertility, 21(8), 75-83.

Oğuz S, Işık S, Çakır Güngör, Seker M, Öğretmen, Z. (2014). Protective efficacy of olive oil for sore nipples during nursing. Journal of Family Medicine and Community Health, 1(4), 1021.

Page T, Lockwood C, Guest K. (2003). Management of nipple pain and/or trauma associated with breastfeeding. JBI Reports, 1, 127-147.

Pezeshki B, Pouredalati M, Zolala S, Moeindarbary S, Kazemi K, Rakhsha M. (2020). Comparison of the effect of aloe vera extract, breast milk, calendit-e, curcumin, lanolin, olive oil, and purslane on healing of breast fissure in lactating mothers: A Systematic Reviw. International Journal of Pediatrics, 8 (2), 10853-10863.
Saeidi R, Tafazoli M, Gholami M, Mazloom R. (2015). New treatment for nipple soreness in breastfeeding mothers: A clinical trial study. Iranian Journal of Neonatology IJN, 6 (2), 48-51.

Sailo ML, Jagadeesh NS, Ranganathan S, Duraipandian C. (2018). Effect of peppermint water on prevention of nipple injury among postnatal mothers subjected to caesarean. İnternational Journal of Nursing Education, 10 (1), 43-48.

Shanazi M, Farshbaf Khalili A, Kamalifard M, Asghari Jafarabadi M, Masoudin K, Esmaeli F. (2015). Comparison of the effects of lanolin, peppermint, and dexpanthenol creams on treatment of traumatic nipples breastfeeding mothers. Journal of Caring Sciences, 4 (4), 297-307.

Şahin H, Yılmaz M, Aykut M, Balci E, Sağıroğlu M, Öztürk A. (2013). Kayseri'de iki toplum sağlığg merkezine başvuran annelerde emzirme sorunları ve risk etmenleri. Türk Pediatri Arşivi. 48, 145-151.

Silva Santos KJ, Santana GS, de Oliveira Vieira T, Santos CADST, Giugliani ERJ, Vieira GO. (2016). Prevalence and factors associated with cracked nipples in the first month postpartum. BMC Pregnancy and Childbirth, 16(1), 209.

Tafazoli M, Saeedi R, Gholami Robatsangi M, Mazloom R. (2010). Aloevera gel vs. lanolin ointment in the treatment of nipple sore: a randomized clinical trial. Tehran University Medical Journal, 67 (10), 699704.

Thabet HA, Mourad MA, Alahadal AM, Alsenany S, Alsaif A. (2013). Prevention of nipple cracks with peppermint water versus breast milk in lactating primiparous women. Life Science Journal, 10 (4), 2010-2017.

Türkiye Nüfus ve Sağlık Araştırması. (2018). Ana Raporu. Erişim Tarihi:01.08.2020, http://www.hips.hacettepe.edu.tr/tnsa2018/rapor/TN SA2018 ana Rapor.pdf

Vieira F, Bachion MM, Mota DD, Munari DB. (2013). A systematic review of the interventions for nipple trauma in breastfeeding mothers. Journal Nursing Scholarsh. 45 (2), 116-125.

Walker M. (2013). Are there any cures for sore nipples?. Clinical Lactation. 4 (3), 106-115.

World Health Organization, UNICEF. (2018). Capture The Moment- Early initation of breastfeeding: The best start of every newborn. New York: WHO, UNICEF, 8-12. 